\title{
Pharmacological Investigations in Glia Culture Model of Inflammation
}

\author{
Fatme Seval Ismail ${ }^{1 * t}$, Franco Corvace ${ }^{2 \dagger}$, Pedro M. Faustmann ${ }^{2}$ and \\ Timo Jendrik Faustmann ${ }^{3}$
}

${ }^{1}$ Department of Neurology, University Hospital Knappschaftskrankenhaus Bochum, Ruhr University Bochum, Bochum, Germany, ${ }^{2}$ Department of Neuroanatomy and Molecular Brain Research, Ruhr University Bochum, Bochum, Germany,

${ }^{3}$ Department of Psychiatry and Psychotherapy, Medical Faculty, Heinrich Heine University Düsseldorf, Düsseldorf, Germany

\section{OPEN ACCESS}

Edited by:

Bi-Wen Peng,

Wuhan University, China

Reviewed by:

Amol K. Bhandage,

Stockholm University, Sweden

*Correspondence:

Fatme Seval Ismail

ismaf88@gmail.com;

FatmeSeval.Ismail@kk-bochum.de

these authors have contributed equally to this work and share first authorship

Specialty section:

This article was submitted to Non-Neuronal Cells,

a section of the journal

Frontiers in Cellular Neuroscience

Received: 30 October 2021 Accepted: 26 November 2021 Published: 16 December 2021

Citation:

Ismail FS, Corvace F, Faustmann PM and Faustmann TJ (2021) Pharmacological Investigations in Glia Culture Model of Inflammation.

Front. Cell. Neurosci. 15:805755. doi: 10.3389/fncel.2021.805755
Astrocytes and microglia are the main cell population besides neurons in the central nervous system (CNS). Astrocytes support the neuronal network via maintenance of transmitter and ion homeostasis. They are part of the tripartite synapse, composed of pre- and postsynaptic neurons and perisynaptic astrocytic processes as a functional unit. There is an increasing evidence that astroglia are involved in the pathophysiology of CNS disorders such as epilepsy, autoimmune CNS diseases or neuropsychiatric disorders, especially with regard to glia-mediated inflammation. In addition to astrocytes, investigations on microglial cells, the main immune cells of the CNS, offer a whole network approach leading to better understanding of non-neuronal cells and their pathological role in CNS diseases and treatment. An in vitro astrocyte-microglia coculture model of inflammation was developed by Faustmann et al. (2003), which allows to study the endogenous inflammatory reaction and the cytokine expression under drugs in a differentiated manner. Commonly used antiepileptic drugs (e.g., levetiracetam, valproic acid, carbamazepine, phenytoin, and gabapentin), immunomodulatory drugs (e.g., dexamethasone and interferon-beta), hormones and psychotropic drugs (e.g., venlafaxine) were already investigated, contributing to better understanding mechanisms of actions of CNS drugs and their pro- or anti-inflammatory properties concerning glial cells. Furthermore, the effects of drugs on glial cell viability, proliferation and astrocytic network were demonstrated. The in vitro astrocyte-microglia co-culture model of inflammation proved to be suitable as unique in vitro model for pharmacological investigations on astrocytes and microglia with future potential (e.g., cancer drugs, antidementia drugs, and toxicologic studies).

Keywords: astrocyte-microglia co-culture model, M5/M30 conditions, inflammation, pharmacology, immunomodulatory drugs, psychotropic drugs, antiepileptic drugs (AEDs)

\section{INTRODUCTION}

Astrocytes and microglia are the main cell population besides neurons in the central nervous system (CNS). Astrocytes represent the largest glia cell population. They are involved in the formation of the blood-brain barrier, support of the ion, water and neurotransmitter homeostasis as well as regulation of neuronal synaptogenesis (Giovannoni and Quintana, 2020). They are part of the tripartite synapse, which includes pre- and postsynaptic neurons and perisynaptic astrocytic processes as a functional unit (Araque et al., 1999; Möller et al., 2007). Importantly, astrocytes can form a syncytium by connecting individual cells to a large network using connexin 43 (Cx43), the main gap junctional protein (Reuss and Unsicker, 1998). Microglia, another type of glia cells, 
are the main immune cells of the CNS. They respond to changes of brain homeostasis under neuroinflammatory conditions with proliferation, activation and release of inflammatory mediators (Gehrmann et al., 1995; Voet et al., 2019).

Moreover, astrocytes and microglia play an important role in neurological diseases such as multiple sclerosis (MS) (Perriot et al., 2018; van der Poel et al., 2019; Wheeler and Quintana, 2019; Cignarella et al., 2020) and epilepsy (Coulter and Steinhäuser, 2015; Çavdar et al., 2019; Fu et al., 2021), but also in psychiatric diseases such as bipolar disorder and schizophrenia (Réus et al., 2015; Peng et al., 2016; Petrasch-Parwez et al., 2020). There is an increasing evidence that glia-mediated neuroinflammation is involved in the pathomechanism of these diseases (Vezzani et al., 2008; Réus et al., 2015; Perriot et al., 2018; Voet et al., 2019).

The involvement of astrocytes and microglia in neuropsychiatric disorders raises the question how these cells besides neurons might be responsive to current pharmacological treatments, especially with link to inflammation. Therefore, this focused mini review will summarize and discuss the major findings of pharmacological investigations in glia culture model of inflammation.

\section{IN VITRO ASTROCYTE-MICROGLIA CO-CULTURE MODEL OF INFLAMMATION}

Since astrocytes and microglia are important players in healthy and diseased brain, Faustmann et al. (2003) developed an astrocyte-microglia co-culture model to study the physiological as well as pathological inflammatory states in the brain depending on the percentage and activation of microglia (Faustmann et al., 2003). Microglia play an important role in the maintenance of normal brain function (Ling and Wong, 1993). In health brain, they can be found as inactive ramified type (RRT), which represents the primary existing phenotype under physiological conditions (Ling and Wong, 1993; Faustmann et al., 2003; Kettenmann et al., 2011). Acute CNS lesions and pathologic changes lead to proliferation and activation of microglia, transitioning from the inactive ramified state via an intermediate form (INT) to the activated form (round phagocytic type, RPT) (Figure 1; Faustmann et al., 2003; Block et al., 2007; Kettenmann et al., 2011). The RRT has small cell bodies (5$10 \mu \mathrm{m}$ ) with a small perinuclear, cytoplasmic rim and thin branching processes longer than the diameter of the cell body (Figure 1C); a large cellular diameter, rare short processes, and several cytoplasmic vacuoles are typical for the activated RPT (Figure 1E); the INT is characterized by some thick pseudopodia longer than the diameter of the cell body and a perinuclear cytoplasmic rim with a few vesicles and vacuoles (Figure 1D; Faustmann et al., 2003). Under physiological conditions, the amount of microglia varies between 5 and 20\% (Faustmann et al., 2003). The pathological activation of microglia occurs through several steps and is mediated by incoming stimuli such as ATP, adenosine, complement factors, cytokines, chemokines and changes in potassium concentration (Chang et al., 2009). As a result of activation, increased astrocyte mobility and a chemotactic gradient, microglia actively migrate to the pathological origin and exert curative or destructive effects depending on various factors (Walter and Neumann, 2009; Kettenmann et al., 2011). Under inflammatory conditions, activated microglia are able to produce neurotrophic factors, pro-inflammatory substances such as interleukin (IL)-6, tumor necrosis factor (TNF) $\alpha$, interferon (IFN)- $\gamma$ as well as antiinflammatory cytokines such as IL-10, transforming growth factor (TGF)- $\beta$ (Ledeboer et al., 2000; Meeuwsen et al., 2003, 2005; Cartier et al., 2005). The effect exerted by microglia seems to depend in particular on stimulation and interaction with other molecules (Czeh et al., 2011; Biber et al., 2014; Chen and Trapp, 2016). The interactions between astrocytes and microglia have a crucial impact on neuroinflammation in the CNS and are not well understood. Murine in vitro astrocyte and microglia cultures are powerful tools to study molecular signaling pathways involved in neuroinflammation (Barbierato et al., 2013; Dambach et al., 2014; Facci et al., 2018; Ismail et al., 2021). In the astrocyte-microglia co-culture model developed by Faustmann et al., 2003, the physiological state is characterized by a microglia fraction of $5-10 \%$ (referred to as M5 co-culture) (Figure 1A), this fraction increases to 30-40\% (M30 co-culture) (Figure 1B) under pathological, inflammatory conditions. In addition to the percentage, the M5or M30-experimental paradigms also produce different microglia phenotypes. While the M5 co-culture contains predominantly resting ramified microglial cells (Figure 1A), more activated microglia are found in the M30 co-culture (Figure 1B; Faustmann et al., 2003; Hinkerohe et al., 2005). Moreover, a positive correlation of percent activated microglia with reduced astroglial $\mathrm{Cx} 43$ expression was demonstrated, suggesting a functional relationship between microglial activation and coupling efficiency in the astroglial network under in vitro conditions (Faustmann et al., 2003). Incubation of the M5 cocultures with the pro-inflammatory cytokines further resulted in microglial activation itself (Hinkerohe et al., 2005). In contrast, incubation of pathological M30 co-cultures with TGF- $\$ 1$ resulted in a decrease of microglial activation including restoration of functional coupling via gap-junctions. Furthermore, IFN- $\beta$ prevented the effects of the pro-inflammatory cytokines TNF$\alpha$, IL-1 $\beta$, and IFN- $\gamma$ in M5 co-cultures (Hinkerohe et al., 2005). Since the presence of microglia under in vivo conditions is considered crucial for the extent of inflammation in various neurological diseases such as MS (Bogie et al., 2014; Giunti et al., 2014) or Alzheimer's disease (Gold and El Khoury, 2015; Heppner et al., 2015; Malik et al., 2015; ElAli and Rivest, 2016), this simple but efficient co-culture model, compared to classical monocultures, allows the mimicking of inflammatory conditions in a defined in vitro assay, thus not only the activation of microglia, but also the response of astrocytes to this activation in terms of bidirectional interactions can be studied (Faustmann et al., 2003; Hinkerohe et al., 2005). Besides the obvious advantage of this established cell culture model over monocultures, which do not take the interactions between astrocytes and microglia into account, the advantage over other co-cultures must also be considered. Most astrocyte-microglia co-cultures are based on two primary cultures (astrocytes and microglia) 

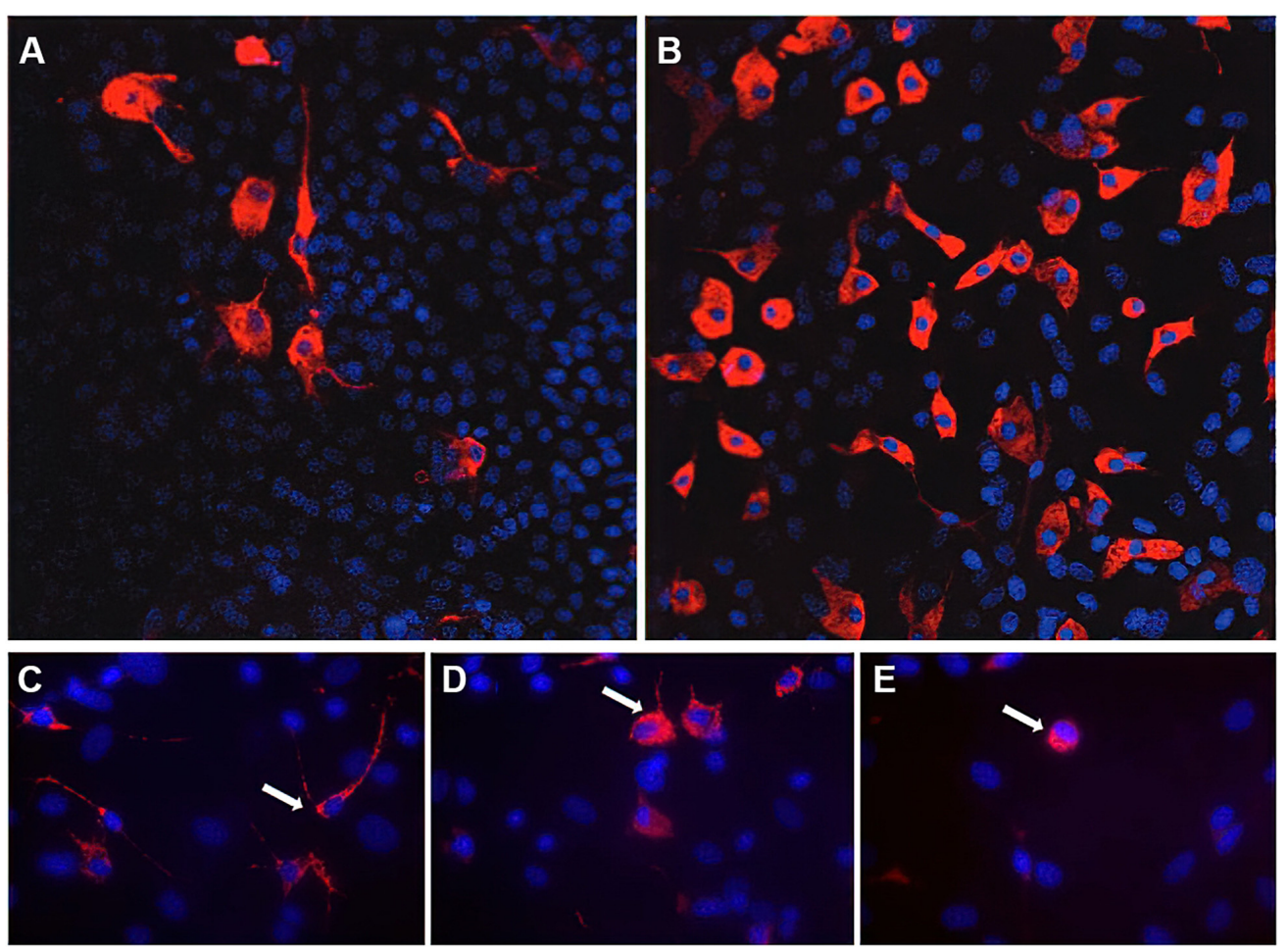

FIGURE 1 | Immunocytochemistry of microglia morphology in M5 und M30 astrocyte-microglia co-cultures. Physiological M5 co-cultures containing 5\% microglia (red) (A). Pathological, inflammatory M30 co-cultures containing 30\% microglia (B) (published by Dambach et al., 2014). Staining with the monoclonal antibody ED-1 allowed the classification of microglia (white arrows) as resting ramified (C), intermediate (D) and activated rounded phagocytic (E) phenotype (published by Ismail et al., 2021). Nuclei (blue) were counterstained with DAPI to visualize the total glial cell number.

cultivated together in different ratios, whereas in the system developed by Faustmann et al. (2003) a much more natural inflammation model is obtained by activation of microglia and concomitant proliferation (Bohatschek et al., 2001; Faustmann et al., 2003; Zhao et al., 2017). Of course, the limitation of the model to tricultures, which include neurons in addition to astrocytes and microglia, must also be considered (Goshi et al., 2020). Such a triculture model mimics neuroinflammatory responses correspondingly more accurately, but overall, due to its uniqueness and ease of reproducibility, the co-culture system established by Faustmann et al., 2003 is an excellent model for studying neuroinflammatory responses between astrocytes and microglia, cell-cell communication and their interaction on pharmaceuticals (Table 1; Hinkerohe et al., 2005, 2010, 2011; Haghikia et al., 2008; Vollmar et al., 2008; Stienen et al., 2011; Dambach et al., 2014; Moinfar et al., 2014; Ismail et al., 2021).

\section{PHARMACOLOGICAL INVESTIGATIONS}

\section{Antiepileptic Drugs}

Several studies provide evidence that astrocytes and microglia are involved in the pathophysiology of epilepsy (Bedner et al., 2015; Berger et al., 2019; Patel et al., 2019; Heuser et al., 2021). Clinical and experimental research showed that epileptic activity can be associated with inflammation due to increased levels of inflammatory mediators in the brain (e.g., IL-1 $\beta$, TNF- $\alpha$, and IL-6), which are produced by glia, neurons, endothelial cells of the blood-brain barrier and peripheral immune cells (Vezzani and Granata, 2005; Vezzani et al., 2011). Additional cellular mechanisms of inflammation such as reactive astrocytosis and activated microglia are well known (Vezzani and Granata, 2005; Vezzani et al., 2011). The anticonvulsant effect of immunomodulatory drugs with anti-inflammatory actions such as adrenocorticotropic hormone $(\mathrm{ACTH})$ and steroids has been demonstrated (Brunson et al., 2002; Granata et al., 2003; Vezzani and Granata, 2005). However, the question remained whether available antiepileptic drugs (AEDs) may have anti-inflammatory effects. For this reason, we have investigated pro-and anti-inflammatory effects of conventional and second-generation AEDs in our astrocytemicroglia co-culture model of inflammation (Table 1). We showed a significant microglial activation in physiological M5 and inflammatory M30 co-cultures after concentrationdependent incubation with valproic acid (VPA) (Dambach et al., 2014). Incubation with gabapentin (GBT) induced no significant alterations in the microglial activation state. Phenytoin (PHE) led to increase of amount of activated microglia (RPT) in M5 co-cultures, whereas incubation of M30 co-cultures with PHE did not affect the microglial phenotypes (Dambach et al., 2014). In another study, sodium channel blockade with PHE significantly reduced the phagocytic activity of 
TABLE 1 | Pharmacological investigations in astrocyte-microglia co-culture model of inflammation.

\begin{tabular}{|c|c|c|c|c|c|c|c|c|c|}
\hline & \multicolumn{4}{|c|}{ M5 (physiological) co-cultures } & \multicolumn{4}{|c|}{ M30 (pathological, inflammatory) co-cultures } & \multirow[b]{2}{*}{ References } \\
\hline & $\begin{array}{c}\text { Microglia } \\
\text { phenotypes }\end{array}$ & $\begin{array}{l}\text { Cytokine } \\
\text { expression }\end{array}$ & $\begin{array}{c}\text { Cx43 } \\
\text { expression }\end{array}$ & $\begin{array}{l}\text { Gap-junctional } \\
\text { communication }\end{array}$ & $\begin{array}{c}\text { Microglia } \\
\text { phenotypes }\end{array}$ & $\begin{array}{c}\text { Cytokine } \\
\text { expression }\end{array}$ & $\begin{array}{c}\text { Cx43 } \\
\text { expression }\end{array}$ & $\begin{array}{l}\text { Gap-junctional } \\
\text { communication }\end{array}$ & \\
\hline Levetiracetam & - & $\mathrm{TGF}-\beta 1 \uparrow$ & $\begin{array}{c}\text { After IL-1 } \beta \text { and } \\
\text { LPS treatment } \\
\text { Cx43 } \leftrightarrow\end{array}$ & $\begin{array}{c}\text { After IL-1 } \beta \text { and } \\
\text { LPS treatment } \\
\leftrightarrow \leftrightarrow\end{array}$ & - & $\begin{array}{c}\mathrm{IL}-1 \beta \downarrow \\
\mathrm{TGF}-\beta 1 \uparrow\end{array}$ & Cx43 个 & $\uparrow$ & $\begin{array}{c}\text { Haghikia et al., } \\
\text { 2008; Stienen } \\
\text { et al., } 2011\end{array}$ \\
\hline Valproic acid & $\begin{array}{c}\text { Activated } \\
\text { microglia } \uparrow\end{array}$ & $\begin{array}{l}\text { TGF- } \beta 1 \leftrightarrow \\
\text { TNF- } \alpha \leftrightarrow\end{array}$ & $\mathrm{C} \times 43 \leftrightarrow$ & - & $\begin{array}{c}\text { Activated } \\
\text { microglia } \uparrow\end{array}$ & $\begin{array}{l}\text { TGF- } \beta 1 \leftrightarrow \\
\text { TNF- } \alpha \leftrightarrow\end{array}$ & Cx43 $\leftrightarrow$ & - & $\begin{array}{c}\text { Dambach et al., } \\
2014\end{array}$ \\
\hline Carbamazepine & Microglia $\leftrightarrow$ & $\begin{array}{l}\text { TGF- } \beta 1 \leftrightarrow \\
\text { TNF- } \alpha \leftrightarrow\end{array}$ & $\mathrm{C} \times 43 \leftrightarrow$ & - & $\begin{array}{c}\text { Activated } \\
\text { microglia } \downarrow \\
\text { Inactivated } \\
\text { microglia } \uparrow\end{array}$ & $\begin{array}{l}\text { TGF- } \beta 1 \leftrightarrow \\
\text { TNF- } \alpha \leftrightarrow\end{array}$ & CX43 ↔ & - & $\begin{array}{c}\text { Dambach et al., } \\
2014\end{array}$ \\
\hline Phenytoin & $\begin{array}{c}\text { Activated } \\
\text { microglia } \uparrow \\
\text { Inactivated } \\
\text { microglia } \downarrow\end{array}$ & $\begin{array}{l}\text { TGF- } \beta 1 \uparrow^{\star} \\
\text { TNF- } \alpha \leftrightarrow\end{array}$ & $\mathrm{C} \times 43 \leftrightarrow$ & - & Microglia $\leftrightarrow$ & $\begin{array}{c}\mathrm{TGF}-\beta 1 \uparrow \\
\mathrm{TNF}-\alpha \uparrow\end{array}$ & Cx43 $\leftrightarrow$ & - & $\begin{array}{c}\text { Dambach et al., } \\
2014\end{array}$ \\
\hline Gabapentin & Microglia $\leftrightarrow$ & $\begin{array}{c}\text { TGF- } \beta 1 \uparrow^{*} \\
\text { TNF- } \alpha \\
\text { undetectable }\end{array}$ & $\mathrm{C} \times 43 \leftrightarrow$ & - & Microglia $\leftrightarrow$ & $\begin{array}{l}\text { TGF- } \beta 1 \uparrow^{\star} \\
\text { TNF- } \alpha \leftrightarrow\end{array}$ & $\mathrm{C} \times 43 \leftrightarrow$ & - & $\begin{array}{c}\text { Dambach et al., } \\
2014\end{array}$ \\
\hline Dexamethasone & $\begin{array}{c}\text { After LPS } \\
\text { treatment } \\
\text { Activated } \\
\text { microglia } \downarrow\end{array}$ & - & $\begin{array}{c}\text { After LPS } \\
\text { treatment } \\
\text { Cx43 } \uparrow\end{array}$ & $\begin{array}{c}\text { After LPS } \\
\text { treatment } \uparrow\end{array}$ & $\begin{array}{c}\text { Activated } \\
\text { microglia } \downarrow^{*} \\
\text { Inactivated } \\
\text { microglia } \uparrow\end{array}$ & - & $\mathrm{C} \times 43 \uparrow$ & $\uparrow^{*}$ & $\begin{array}{c}\text { Hinkerohe } \\
\text { et al., } 2010 \text {, } \\
2011\end{array}$ \\
\hline Interferon- $\beta$ & $\begin{array}{c}\text { After TNF- } \alpha \text {, } \\
\text { IL-1 } 1 \beta \text {, IFN- } \gamma \\
\text { treatment } \\
\text { Activated } \\
\text { microglia } \downarrow\end{array}$ & - & - & $\begin{array}{l}\text { After TNF- } \alpha, \\
\text { IL- } 1 \beta, \text { IFN- } \gamma \\
\text { treatment } \uparrow\end{array}$ & - & - & - & - & $\begin{array}{l}\text { Hinkerohe } \\
\text { et al., } 2005\end{array}$ \\
\hline Venlafaxine & - & - & - & $\leftrightarrow$ & $\begin{array}{c}\text { Activated } \\
\text { microglia } \downarrow \\
\text { Inactivated } \\
\text { microglia } \uparrow\end{array}$ & $\begin{array}{c}\text { TGF- } \beta \uparrow \\
\text { IL- } 6 \downarrow \\
\text { IFN- } \gamma \downarrow \\
\text { IL-10↔ }\end{array}$ & - & $\uparrow^{*}$ & $\begin{array}{l}\text { Vollmar et al., } \\
2008\end{array}$ \\
\hline Ammonia & $\begin{array}{c}\text { Activated } \\
\text { microglia } \uparrow \\
\text { Inactivated } \\
\text { microglia } \downarrow\end{array}$ & - & $\mathrm{C} \times 43 \leftrightarrow$ & - & $\begin{array}{c}\text { Activated } \\
\text { microglia } \uparrow \\
\text { Inactivated } \\
\text { microglia } \downarrow\end{array}$ & - & $\mathrm{C} \times 43 \uparrow$ & - & $\begin{array}{l}\text { Ismail et al., } \\
2021\end{array}$ \\
\hline
\end{tabular}

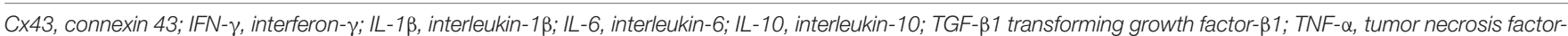
$\alpha$; IFN- $\beta$, interferon- $\beta$; LPS, lipopolysaccharide.

$\uparrow$, increase; $\downarrow$, decrease; $\leftrightarrow$, unchanged; -, not available; *, at higher concentration.

lipopolysaccharide (LPS)-activated microglia (Black et al., 2009). Furthermore, carbamazepine (CBZ) significantly reduced the amount of activated microglial cells in M30 co-cultures. This finding is consistent with anti-inflammatory properties of CBZ in rat models with regard to pain/hyperalgesia (Bianchi et al., 1995; Iwamoto et al., 2011). In addition, increased TGF- $\beta 1$ and TNF- $\alpha$ cytokine levels were detected after incubation with PHE in M30 co-cultures. The other AEDs VPA, GBT, and CBZ did not alter the TNF- $\alpha$ cytokine expression in our co-culture model. The glial cell viability was reduced after concentration-dependent incubation with PHE and CBZ, especially in M30 co-cultures (Dambach et al., 2014). Another in vitro study focusing on metabolic effects of AEDs showed CBZ-induced stress on primary astrocytes at all concentrations, but low concentrations of GBP did not change the metabolic activities of astrocytes and did not have toxic effects on these cells (Pavone and Cardile, 2003).

Moreover, Haghikia et al. (2008) showed that treatment of inflammatory glia co-culture model with levetiracetam
(LEV), an established second-generation AED, reconstituted the impaired astroglial gap junction coupling and membrane resting potential (MRP) to non-inflammatory level. In another study, LEV restored IL-1 $\beta$-mediated MRP depolarization to physiological levels and promoted anti-inflammatory TGF- $\beta 1$ expression in inflammatory and control astrocyte-microglia co-cultures (Stienen et al., 2011). LEV and TGF- $\beta 1$ induced comparable effects on the generation of astrocyte voltage-gated currents in inflammatory co-cultures and the effects of LEV were prevented by antibody to TGF- $\beta 1$, indicating that the anti-inflammatory effects of LEV on astroglia are mediated via TGF- $\beta 1$ regulation. In addition, LEV suppressed microglial activation including morphological changes, phagocytic activity and cytokine expression in contrast to VPA and CBZ during epileptogenesis (Itoh et al., 2019). Other study findings suggested neuroprotective effects of LEV via anti-angiogenesis and antiinflammatory activities against blood-brain barrier dysfunction in the acute phase of epileptogenesis after status epilepticus 
(Itoh et al., 2016; Ismail and Faustmann, 2021). In addition, LEV reduced reactive gliosis and expression levels of IL-1 $\beta$ in the hippocampus and the piriform cortex of chronic epileptic rats unlike VPA (Kim et al., 2010).

In summary, these data suggest that astrocyte dysfunction and glia-mediated inflammation play an important role in epilepsy. So, astrocytes and microglia are potential novel targets for alternative anti-epileptogenic therapies.

\section{Psychotropic Drugs}

According to the hypothesis that cytokines may play a role in the pathophysiology of psychiatric disorders ( $\mathrm{Na}$ et al., 2014; Kim et al., 2016; van den Ameele et al., 2016), further investigations on glia cells offer new findings with regard to CNS inflammation, psychiatric disorders and pharmacological treatment. Venlafaxine, a norepinephrine-serotonin reuptake inhibitor and frequently used drug in mood disorders, revealed anti-inflammatory effects in our astroglia-microglia co-culture model (Table 1). In M30 co-cultures, microglia changed to the RRT, depolarization of membrane resting potential was reversed and an increase of TGF- $\beta$ level was found in parallel with a reduction of IFN- $\gamma$ and IL-6 (Vollmar et al., 2008). Corresponding, IL-6 is a major cytokine under pathological conditions in the CNS such as MS, Alzheimer's disease, trauma, and meningitis (Gruol and Nelson, 1997). Consistent with these findings, venlafaxine was found to be neuroprotective after stroke events in rats (Zepeda et al., 2016) and a decreased microglia staining was described in dorsal root ganglia in a rat model of neuropathic pain (Zychowska et al., 2015). Metabolic profiling of astrocytes treated with venlafaxine revealed effects on amino acids metabolism, cellular growth and proliferation (Sun et al., 2017). In addition, a hyper-ramification of microglia was found in a mice-model of depression and could be reversed by venlafaxine (Hellwig et al., 2016). In a prenatal stress model in Wistar rats, venlafaxine showed protective effects on microglia (Obuchowicz et al., 2020). Further, venlafaxine had inhibitory effects on superoxide generation in LPS-stimulated BV-2 microglia cell line (Dubovický et al., 2014). In conclusion, these findings indicate significant effects of the psychotropic drug venlafaxine on glial cells, underlying additional pharmacological mechanisms.

\section{Mechanisms of Action of Neurotrophic Drugs on Glial Cells}

In recent years, more and more studies focused on mechanisms of action of neurotrophic drugs on glial cells. In our astrocyte-microglia co-culture model of inflammation, the antiinflammatory properties of the AED LEV on electrophysiological properties of astroglia have been shown to be mediated via TGF $\beta 1$ regulation (Stienen et al., 2011). Combination of a $\mu$-opioid receptor antagonist at ultralow concentrations and a $\mu$-opioid receptor agonist with LEV managed to activate the $\mathrm{G}_{\mathrm{i} / \mathrm{o}}$ protein and $\mathrm{Na}^{+} / \mathrm{K}^{+}$-ATPase activity, inhibit the $\mathrm{G}_{\text {s }}$ protein, and decrease the release of IL- $1 \beta$, contributing to restoration of inflammation-reactive astrocytes (Block et al., 2013). In addition, this combination with LEV downregulated also the glutamateevoked intracellular $\mathrm{Ca}^{2+}$ release and toll-like receptor 4 (TLR4) expression on inflammatory active astrocyte cultures (Hansson et al., 2018). Another study showed combined mechanisms of LEV in rat cortical primary cultured astrocytes including inhibition of AMPA- and adenophostin A (AdA)-induced astroglial release of kynurenine-pathway metabolites, inhibition of IFN- $\gamma$-induced inositol 1,4,5-trisphosphate (IP3) receptor activation. Further, LEV reduced the IFN- $\gamma$-induced release of cinnabarinic and quinolinic acid, and enhanced the stimulatory effects of IFN- $\gamma$ on kynurenic acid (Fukuyama and Okada, 2018). Kynurenic acid is known as anti-absence and anti-convulsive metabolite, whereas cinnabarinic acid is a pro-absence and quinolinic acid a pro-convulsive metabolite. Further, it has been demonstrated that LEV inhibits $A \beta$-induced vesicular glutamate release from human astrocytes (Sanz-Blasco et al., 2016). Another study observed that treatment with LEV stimulated the expression of both brain-derived neurotrophic factor (BDNF) and inducible nitric oxide synthase (iNOS) in a concentrationdependent manner on rat cortical astrocyte cultures, suggesting neuroprotective and anti-inflammatory effects (Cardile et al., 2003). LEV reduced reactive astrogliosis and microgliosis via attenuation of IL-1 $\beta$ and IL-1RI expression levels in chronic epileptic rats (Kim et al., 2010). The IL-1 $\beta$ function was linked to inhibition of gap junctions in astrocytes and epileptic activity. These results support multiple anti-inflammatory mechanisms of actions of LEV in neuroglia, especially with regard to epileptic brains. In contrast, VPA did not change the IL-1 $\beta$ and IL-1RI expression levels in astrocytes and microglia (Kim et al., 2010). LEV also attenuated the expression of TNF- $\alpha$ and IL- $1 \beta$ in animal model of status epilepticus. In this model, VPA also inhibited the pro-inflammatory cytokine expression, whereas CBZ did not have effects on cytokines. Moreover, LEV was able to suppress mononuclear phagocyte activation in contrast to VPA and CBZ. The BV-2 microglial activation was also not affected by VPA and CBZ compared to LEV (Itoh et al., 2019). A recent study demonstrated that the number of GABAergic synapses is reduced by VPA-exposed astrocytes, indicating impaired synaptogenesis of inhibitory neurons by VPA-exposed astrocytes (Takeda et al., 2021). It has been discussed that the altered GABAergic synapse formation and synaptic transmission may be caused by a reduced level of protein tyrosine phosphatase receptor type delta (PTPRD), because PTPRD is involved in GABAergic presynaptic differentiation (Takeda et al., 2021). This may indicate an impaired astrocyte-mediated neurodevelopment in case of maternal use of VPA. With regard to treatment with CBZ, upregulated $\mathrm{A}_{1}$-receptor mRNA expression in primary astrocyte cultures from brain regions with low receptor expression was detected and linked to phosphoinositol signaling pathway (Biber et al., 1999). Otherwise, CBZ attenuated LPS-induced iNOS expression predominantly by inhibiting phosphatidylinositol 3-kinase (PI-3K)/Akt signaling pathway in activated BV2 microglial cells (Wang et al., 2014). Acute and chronic treatment of primary cultured astrocytes with CBZ inhibited excitatory astroglial glutamatergic transmission associated with IP3-R and AMPA-R. Further, the pro-inflammatory cytokines IFN- $\gamma$ and TNF- $\alpha$ induced astroglial L-glutamate release was inhibited by CBZ via chronically activation of adenosine $\mathrm{A}_{2 \mathrm{~A}}$ receptor, suggesting potential anti-inflammatory effects of CBZ 
in neuropsychiatric disorders associated with pro-inflammatory cytokines (Okada et al., 2019).

The neuronal mechanism of action of the antidepressant venlafaxine is believed to be mediated by uptake inhibition of norepinephrine and serotonin. Serotonin uptake is already inhibited at low doses, whereas at high doses norepinephrine and serotonin uptakes are inhibited (Harvey et al., 2000). Astrocytes express norepinephrine transporters and could inactivate norepinephrine that escapes neuronal re-uptake. This effect seems to be inactivated by antidepressants such as venlafaxine (Inazu et al., 2003). On intracellular level, the selective serotonin and serotonin norepinephrine reuptake inhibitors (SSRI and SNRI) decreased TNF- $\alpha$ and nitric oxide production in microglia. This mechanism is suggested to be cAMP mediated, suggesting that cAMP signaling is involved in regulation of the anti-inflammatory response. This effect was induced more by fluoxetine and paroxetine compared to venlafaxine (Tynan et al., 2012). Further, venlafaxine regulated inflammation in astrocytes by inhibition of JNK1 activity and STAT3 basal activity, which reduces the production of IL- 6 and IL-1 $\beta$. This effect on STAT3 was independently from a previous induction by a cytokine mixture (comprising complement component 1q, TNF- $\alpha$, IL-1 $1 \alpha$ ). Venlafaxine here revealed a low cytotoxicity on astrocytes compared to other antidepressants (He et al., 2021). Additionally, glioma cells pretreated with venlafaxine and isoproterenol revealed an increased p90Rsk phosphorylation compared to isoproterenol alone, indicating further intracellular effects of venlafaxine on neuro-glial pathways (Khawaja et al., 2004).

In summary, future studies are necessary to reveal further mechanisms of action of neurotrophic drugs with regard to glial cells, because not only neuronal modification and excitability are crucial, but also aspects of glia-mediated pathomechanisms, especially glia-induced inflammation.

\section{Immunomodulatory Drugs}

A link between inflammation and glial cells in inflammatory CNS diseases, e.g., autoimmune diseases such as MS or infection diseases such as meningitis suggested a potential regulatory effect of dexamethasone and IFN- $\beta$ on glial cells. In our glial coculture model of inflammation, dexamethasone reversed an LPSinduced microglial activation, compromised astroglia membrane potential, cellular coupling and $\mathrm{Cx} 43$ expression (Hinkerohe et al., 2010), indicating anti-inflammatory and regulatory effects on glial network (Table 1). Consistent with these findings, dexamethasone reduced neuroinflammatory response and migration of LPS-activated microglia BV2 cells (Hui et al., 2020). Interestingly, Park et al., 2019 showed that dexamethasone induces a specific form of ramified microglia with missing microglia signature genes, e.g., TMEM119 or P2RY12, leading to the conclusion of a dexamethasone-induced dysfunctional microglia type (Park et al., 2019). Further, $\beta 2$-adrenoreceptormediated inflammation can be reduced by dexamethasone in astrocytes and microglia (Ryan et al., 2020). Dexamethasone significantly reduced seizure-induced microglia activation in rats and could reduce the long-term effects of first-time seizures (Fox et al., 2020). In an experimental autoimmune encephalomyelitis model, dexamethasone delayed the inflammatory activation of microglia and astrocytes in the white matter of spinal cord (Nam et al., 2021). In our co-culture model, pre-incubation with IFN- $\beta$ prevented microglial activation in the physiological M5 co-culture despite use of TNF- $\alpha$, IL- $1 \beta$, and IFN- $\gamma$ as activators (Hinkerohe et al., 2005). In addition, IFN- $\beta$ mediated the release of anti-inflammatory IL-10 from microglia in mice (Lobo-Silva et al., 2017) and reduced the number of reactivated microglia in a retinal model (Behnke and Langmann, 2020).

In terms of connectivity, rapidly proliferating astrocytes exposed to dexamethasone failed to express any assemblies (Landis et al., 1991). Interestingly, dexamethasone increased the gap junctional intercellular communication in our M30 co-cultures and reduced it in rat and human glioma cell lines (Hinkerohe et al., 2011). Further, the hetero-cellular gap-junctional coupling between F98 glioma cells and glia cells was reduced by dexamethasone in our co-culture model (Ismail et al., 2017).

Taken together, several studies strongly indicate regulatory effects on inflammatory activation, cytokine release and functional coupling by dexamethasone and IFN- $\beta$ in glial networks.

\section{Others}

Hepatic encephalopathy (HE) is a neuropathological condition caused by acute or chronic liver failure due to hyperammonemia and impaired detoxification of ammonia by the astrocytic glutamine synthetase, resulting in astrocyte swelling (Brusilow et al., 2010). It is known that microglia may contribute to the astrocyte swelling induced by ammonia (Rao et al., 2013). In our M30 co-culture model, ammonia reduced the glia-cell viability (Ismail et al., 2021). Furthermore, microglial activation was detected after incubation with ammonia under physiological and pathological conditions (Table 1). Ammonia effects on $\mathrm{Cx} 43$ and aquaporin 4 expression were limited (Ismail et al., 2021). The microglial activation was consistent with previously described findings of up-regulated microglia activation marker ionized calcium-binding adaptor molecule-1 (Iba-1) in postmortem brain tissues (from HE patients) and cultured microglia (treated with ammonia) (Zemtsova et al., 2011). In another study, ammonia attenuated LPS-induced microglia reactivity including upregulation of pro-inflammatory cytokines in an astrocytedependent way (Karababa et al., 2017). Studies about effects of ammonia on astrocytes and microglia contribute to better understanding of pathophysiological mechanisms of HE.

\section{CONCLUSION}

The in vitro astrocyte-microglia co-culture model of inflammation developed by Faustmann et al. (2003) allowed to study the endogenous inflammatory reaction and the cytokine expression under drugs in a differentiated manner. In addition to astrocytes, investigations on microglia offer a whole network approach leading to better understanding of non-neuronal cells and their pathological role in CNS diseases and treatment. Effects of commonly used AEDs (e.g., LEV, VPA, CBZ, GBP, and 
PHE), immunomodulatory drugs (e.g., dexamethasone, IFN- $\beta$ ) and psychotropic drugs (e.g., venlafaxine) have been already demonstrated, contributing to better understanding mechanisms of actions of CNS drugs and their pro- or anti-inflammatory properties concerning glial cells. Furthermore, influence of drugs on glial cell viability, proliferation and astrocytic network has been shown. The in vitro astrocyte-microglia co-culture model of inflammation proved to be suitable as unique in vitro model for pharmacological investigations on astrocytes and microglia with future potential (e.g., cancer drugs, antidementia drugs, and toxicologic studies). Even more, astrocytes and microglia as main glia cells are novel therapeutic targets for future treatment perspectives using the glia co-culture model of inflammation.

\section{REFERENCES}

Araque, A., Parpura, V., Sanzgiri, R. P., and Haydon, P. G. (1999). Tripartite synapses: glia, the unacknowledged partner. Trends Neurosci. 22, 208-215. doi: 10.1016/s0166-2236(98)01349-6

Barbierato, M., Facci, L., Argentini, C., Marinelli, C., Skaper, S. D., and Giusti, P. (2013). Astrocyte-microglia cooperation in the expression of a proinflammatory phenotype. CNS Neurol. Disord. Drug Targets 12, 608-618. doi: 10.2174/18715273113129990064

Bedner, P., Dupper, A., Hüttmann, K., Müller, J., Herde, M. K., Dublin, P., et al. (2015). Astrocyte uncoupling as a cause of human temporal lobe epilepsy. Brain: J. Neurol. 138, 1208-1222. doi: 10.1093/brain/awv067

Behnke, V., and Langmann, T. (2020). IFN- $\beta$ signaling dampens microglia reactivity but does not prevent from light-induced retinal degeneration. Biochem. Biophys. Rep. 24:100866. doi: 10.1016/j.bbrep.2020.100866

Berger, T. C., Vigeland, M. D., Hjorthaug, H. S., Etholm, L., Nome, C. G., Taubøll, E., et al. (2019). Neuronal and glial DNA methylation and gene expression changes in early epileptogenesis. PLoS One 14:e0226575. doi: 10.1371/journal. pone. 0226575

Bianchi, M., Rossoni, G., Sacerdote, P., Panerai, A. E., and Berti, F. (1995). Carbamazepine exerts anti-inflammatory effects in the rat. Eur. J. Pharmacol. 294, 71-74. doi: 10.1016/0014-2999(95)00516-1

Biber, K., Fiebich, B. L., Gebicke-Härter, P., and van Calker, D. (1999). Carbamazepine-induced upregulation of adenosine A1-receptors in astrocyte cultures affects coupling to the phosphoinositol signaling pathway. Neuropsychopharmacol. : Off. Publ. Am. College Neuropsychopharmacol. 20, 271-278. doi: 10.1016/S0893-133X(98)00059-1

Biber, K., Owens, T., and Boddeke, E. (2014). What is microglia neurotoxicity (Not)? Glia 62, 841-854. doi: 10.1002/glia.22654

Black, J. A., Liu, S., and Waxman, S. G. (2009). Sodium channel activity modulates multiple functions in microglia. Glia 57, 1072-1081. doi: 10.1002/glia.20830

Block, L., Björklund, U., Westerlund, A., Jörneberg, P., Biber, B., and Hansson, E. (2013). A new concept affecting restoration of inflammation-reactive astrocytes. Neuroscience 250, 536-545. doi: 10.1016/j.neuroscience.2013.07.033

Block, M. L., Zecca, L., and Hong, J. S. (2007). Microglia-mediated neurotoxicity: uncovering the molecular mechanisms. Nat. Rev. Neurosci. 8, 57-69. doi: 10. 1038/nrn2038

Bogie, J. F., Stinissen, P., and Hendriks, J. J. (2014). Macrophage subsets and microglia in multiple sclerosis. Acta Neuropathol. 128, 191-213. doi: 10.1007/ s00401-014-1310-2

Bohatschek, M., Kloss, C. U., Kalla, R., and Raivich, G. (2001). In vitro model of microglial deramification: ramified microglia transform into amoeboid phagocytes following addition of brain cell membranes to microglia-astrocyte cocultures. J. Neurosci. Res. 64, 508-522. doi: 10.1002/jnr.1103

Brunson, K. L., Avishai-Eliner, S., and Baram, T. Z. (2002). ACTH treatment of infantile spasms: mechanisms of its effects in modulation of neuronal excitability. Int. Rev. Neurobiol. 49, 185-197. doi: 10.1016/s0074-7742(02) 49013-7

Brusilow, S. W., Koehler, R. C., Traystman, R. J., and Cooper, A. J. (2010). Astrocyte glutamine synthetase: importance in hyperammonemic syndromes and potential target for therapy. Neurother.: J. Am. Soc. Exp. NeuroTherapeutics 7, 452-470. doi: 10.1016/j.nurt.2010.05.015

\section{AUTHOR CONTRIBUTIONS}

FSI, FC, and TJF prepared the manuscript. All authors were responsible for concepts and design, contributed intellectually, acquired, analyzed, and interpreted the data, read and approved the submission, and agreed to be accountable for the content of the work.

\section{ACKNOWLEDGMENTS}

We acknowledge support from the Open Access Publication Funds of the Ruhr University Bochum.

Cardile, V., Pavone, A., Gulino, R., Renis, M., Scifo, C., and Perciavalle, V. (2003). Expression of brain-derived neurotrophic factor (BDNF) and inducible nitric oxide synthase (iNOS) in rat astrocyte cultures treated with Levetiracetam. Brain Res. 976, 227-233. doi: 10.1016/s0006-8993(03)02720-3

Cartier, L., Hartley, O., Dubois-Dauphin, M., and Krause, K. H. (2005). Chemokine receptors in the central nervous system: role in brain inflammation and neurodegenerative diseases. Brain Res. Brain Res. Rev. 48, 16-42. doi: 10.1016/j. brainresrev.2004.07.021

Çavdar, S., Kuvvet, Y., Sur-Erdem, I., Özgür, M., and Onat, F. (2019). Relationships between astrocytes and absence epilepsy in rat: an experimental study. Neurosci. Lett. 712:134518. doi: 10.1016/j.neulet.2019.134518

Chang, R. C., Chiu, K., Ho, Y. S., and So, K. F. (2009). Modulation of neuroimmune responses on glia in the central nervous system: implication in therapeutic intervention against neuroinflammation. Cell. Mol. Immunol. 6, 317-326. doi: 10.1038/cmi.2009.42

Chen, Z., and Trapp, B. D. (2016). Microglia and neuroprotection. J. Neurochem. 136(Suppl. 1), 10-17.

Cignarella, F., Filipello, F., Bollman, B., Cantoni, C., Locca, A., Mikesell, R., et al. (2020). TREM2 activation on microglia promotes myelin debris clearance and remyelination in a model of multiple sclerosis. Acta Neuropathol. 140, 513-534. doi: 10.1007/s00401-020-02193-z

Coulter, D. A., and Steinhäuser, C. (2015). Role of astrocytes in epilepsy. Cold Spring Harb. Perspect. Med. 5:a022434.

Czeh, M., Gressens, P., and Kaindl, A. M. (2011). The yin and yang of microglia. Dev. Neurosci. 33, 199-209.

Dambach, H., Hinkerohe, D., Prochnow, N., Stienen, M. N., Moinfar, Z., Haase, C. G., et al. (2014). Glia and epilepsy: experimental investigation of antiepileptic drugs in an astroglia/microglia co-culture model of inflammation. Epilepsia 55, 184-192. doi: 10.1111/epi.12473

Dubovický, M., Császár, E., Melicherčíková, K., Kuniaková, M., and Račková, L. (2014). Modulation of microglial function by the antidepressant drug venlafaxine. Interdisciplinary Toxicol. 7, 201-207. doi: 10.2478/intox-20140029

ElAli, A., and Rivest, S. (2016). Microglia in Alzheimer's disease: a multifaceted relationship. Brain Behav. Immun. 55, 138-150. doi: 10.1016/j.bbi.2015.07.021

Facci, L., Barbierato, M., and Skaper, S. D. (2018). Astrocyte/Microglia cocultures as a model to study neuroinflammation. Methods Mol. Biol. 1727, 127-137. doi: 10.1007/978-1-4939-7571-6_10

Faustmann, P. M., Haase, C. G., Romberg, S., Hinkerohe, D., Szlachta, D., Smikalla, D., et al. (2003). Microglia activation influences dye coupling and Cx43 expression of the astrocytic network. Glia 42, 101-108. doi: 10.1002/glia.10141

Fox, P., Mithal, D. S., Somogyi, J. R., Vien, A. C., Sanchez, R. M., and Koh, S. (2020). Dexamethasone after early-life seizures attenuates increased susceptibility to seizures, seizure-induced microglia activation and neuronal injury later in life. Neurosci. Lett. 728:134953. doi: 10.1016/j.neulet.2020.134953

Fu, M., Zhu, Y., Zhang, J., Wu, W., Sun, Y., Zhang, X., et al. (2021). MicroRNA221-3p suppresses the microglia activation and seizures by inhibiting of HIF-1 $\alpha$ in valproic acid-resistant epilepsy. Front. Pharmacol. 12:714556. doi: 10.3389/ fphar.2021.714556

Fukuyama, K., and Okada, M. (2018). Effects of levetiracetam on astroglial release of kynurenine-pathway metabolites. Br. J. Pharmacol. 175, 4253-4265. doi: $10.1111 / \mathrm{bph} .14491$ 
Gehrmann, J., Matsumoto, Y., and Kreutzberg, G. W. (1995). Microglia: intrinsic immuneffector cell of the brain. Brain Res. Brain Res. Rev. 20, 269-287. doi: 10.1016/0165-0173(94)00015-h

Giovannoni, F., and Quintana, F. J. (2020). The role of astrocytes in CNS inflammation. Trends Immunol. 41, 805-819.

Giunti, D., Parodi, B., Cordano, C., Uccelli, A., and Kerlero de Rosbo, N. (2014). Can we switch microglia's phenotype to foster neuroprotection? Focus on multiple sclerosis. Immunology 141, 328-339. doi: 10.1111/imm.12177

Gold, M., and El Khoury, J. (2015). $\beta$-amyloid, microglia, and the inflammasome in Alzheimer's disease. Semin. Immunopathol. 37, 607-611.

Goshi, N., Morgan, R. K., Lein, P. J., and Seker, E. (2020). A primary neural cell culture model to study neuron, astrocyte, and microglia interactions in neuroinflammation. J. Neuroinflamm. 17:155. doi: 10.1186/s12974-020-0 1819-z

Granata, T., Fusco, L., Gobbi, G., Freri, E., Ragona, F., Broggi, G., et al. (2003). Experience with immunomodulatory treatments in Rasmussen's encephalitis. Neurology 61, 1807-1810.

Gruol, D. L., and Nelson, T. E. (1997). Physiological and pathological roles of interleukin-6 in the central nervous system. Mol. Neurobiol. 15, 307-339. doi: 10.1007/BF02740665

Haghikia, A., Ladage, K., Hinkerohe, D., Vollmar, P., Heupel, K., Dermietzel, R., et al. (2008). Implications of antiinflammatory properties of the anticonvulsant drug levetiracetam in astrocytes. J. Neurosci. Res. 86, 1781-1788. doi: 10.1002/ jnr.21639

Hansson, E., Björklund, U., Skiöldebrand, E., and Rönnbäck, L. (2018). Antiinflammatory effects induced by pharmaceutical substances on inflammatory active brain astrocytes-promising treatment of neuroinflammation. J. Neuroinflamm. 15:321. doi: 10.1186/s12974-018-1361-8

Harvey, A. T., Rudolph, R. L., and Preskorn, S. H. (2000). Evidence of the dual mechanisms of action of venlafaxine. Arch. Gen. Psychiatry 57, 503-509. doi: 10.1001/archpsyc.57.5.503

He, J. H., Liu, R. P., Peng, Y. M., Guo, Q., Zhu, L. B., Lian, Y. Z., et al. (2021). Differential and paradoxical roles of new-generation antidepressants in primary astrocytic inflammation. J. Neuroinflamm. 18:47. doi: 10.1186/s12974-02102097-z

Hellwig, S., Brioschi, S., Dieni, S., Frings, L., Masuch, A., Blank, T., et al. (2016). Altered microglia morphology and higher resilience to stress-induced depression-like behavior in CX3CR1-deficient mice. Brain Behav. Immunity 55, 126-137. doi: 10.1016/j.bbi.2015.11.008

Heppner, F. L., Ransohoff, R. M., and Becher, B. (2015). Immune attack: the role of inflammation in Alzheimer disease. Nat. Rev. Neurosci. 16, 358-372. doi: $10.1038 / \mathrm{nrn} 3880$

Heuser, K., de Curtis, M., and Steinhäuser, C. (2021). Editorial: glial dysfunction in epileptogenesis. Front. Neurol. 12:716308. doi: 10.3389/fneur.2021.716308

Hinkerohe, D., Smikalla, D., Haghikia, A., Heupel, K., Haase, C. G., Dermietzel, R., et al. (2005). Effects of cytokines on microglial phenotypes and astroglial coupling in an inflammatory coculture model. Glia 52, 85-97. doi: 10.1002/glia. 20223

Hinkerohe, D., Smikalla, D., Schoebel, A., Haghikia, A., Zoidl, G., Haase, C. G., et al. (2010). Dexamethasone prevents LPS-induced microglial activation and astroglial impairment in an experimental bacterial meningitis co-culture model. Brain Res. 1329, 45-54. doi: 10.1016/j.brainres.2010.03.012

Hinkerohe, D., Wolfkühler, D., Haghikia, A., Meier, C., Faustmann, P. M., and Schlegel, U. (2011). Dexamethasone differentially regulates functional membrane properties in glioma cell lines and primary astrocytes in vitro. J. Neuro-Oncol. 103, 479-489. doi: 10.1007/s11060-010-0456-6

Hui, B., Yao, X., Zhang, L., and Zhou, Q. (2020). Dexamethasone sodium phosphate attenuates lipopolysaccharide-induced neuroinflammation in microglia BV2 cells. Naunyn-Schmiedeberg's Arch. Pharmacol. 393, 1761-1768. doi: 10.1007/ s00210-019-01775-3

Inazu, M., Takeda, H., and Matsumiya, T. (2003). Functional expression of the norepinephrine transporter in cultured rat astrocytes. J. Neurochem. 84, 136144. doi: 10.1046/j.1471-4159.2003.01514.x

Ismail, F. S., and Faustmann, P. M. (2021). Experimental investigations of antiepileptic drugs in astrocytes-microglia co-cultures suggest possible protective effects on astrocytes during early epileptogenesis. Epilepsia 62, 22972298. doi: 10.1111/epi.16968

Ismail, F. S., Faustmann, T. J., Corvace, F., Tsvetanova, A., Moinfar, Z., and Faustmann, P. M. (2021). Ammonia induced microglia activation was associated with limited effects on connexin 43 and aquaporin 4 expression in an astrocyte-microglia co-culture model. BMC Neurosci. 22:21. doi: 10.1186/ s12868-021-00628-1

Ismail, F. S., Moinfar, Z., Prochnow, N., Dambach, H., Hinkerohe, D., Haase, C. G., et al. (2017). Dexamethasone and levetiracetam reduce hetero-cellular gap-junctional coupling between F98 glioma cells and glial cells in vitro. J. Neuro-Oncol. 131, 469-476. doi: 10.1007/s11060-016-2324-5

Itoh, K., Ishihara, Y., Komori, R., Nochi, H., Taniguchi, R., Chiba, Y., et al. (2016). Levetiracetam treatment influences blood-brain barrier failure associated with angiogenesis and inflammatory responses in the acute phase of epileptogenesis in post-status epilepticus mice. Brain Res. 1652, 1-13. doi: 10.1016/j.brainres. 2016.09.038

Itoh, K., Taniguchi, R., Matsuo, T., Oguro, A., Vogel, C., Yamazaki, T., et al. (2019). Suppressive effects of levetiracetam on neuroinflammation and phagocytic microglia: a comparative study of levetiracetam, valproate and carbamazepine. Neurosci. Lett. 708:134363. doi: 10.1016/j.neulet.2019.134363

Iwamoto, T., Takasugi, Y., Higashino, H., Ito, H., Koga, Y., and Nakao, S. (2011). Antinociceptive action of carbamazepine on thermal hypersensitive pain at spinal level in a rat model of adjuvant-induced chronic inflammation. J. Anesthesia 25, 78-86. doi: 10.1007/s00540-010-1046-7

Karababa, A., Groos-Sahr, K., Albrecht, U., Keitel, V., Shafigullina, A., Görg, B., et al. (2017). Ammonia attenuates LPS-induced upregulation of proinflammatory cytokine mRNA in co-cultured Astrocytes and Microglia. Neurochem. Res. 42, 737-749. doi: 10.1007/s11064-016-2060-4

Kettenmann, H., Hanisch, U. K., Noda, M., and Verkhratsky, A. (2011). Physiology of microglia. Phys. Rev. 91, 461-553.

Khawaja, X. Z., Storm, S., and Liang, J. J. (2004). Effects of venlafaxine on p90Rsk activity in rat C6-gliomas and brain. Neurosci. Lett. 372, 99-103. doi: 10.1016/j. neulet.2004.09.029

Kim, J. E., Choi, H. C., Song, H. K., Jo, S. M., Kim, D. S., Choi, S. Y., et al. (2010). Levetiracetam inhibits interleukin-1 beta inflammatory responses in the hippocampus and piriform cortex of epileptic rats. Neurosci. Lett. 471, 94-99. doi: 10.1016/j.neulet.2010.01.018

Kim, Y. K., Na, K. S., Myint, A. M., and Leonard, B. E. (2016). The role of pro-inflammatory cytokines in neuroinflammation, neurogenesis and the neuroendocrine system in major depression. Progress Neuro-Psychopharmacol. Biol. Psychiatry 64, 277-284. doi: 10.1016/j.pnpbp.2015.06.008

Landis, D. M., Weinstein, L. A., and Skordeles, C. J. (1991). Effects of dexamethasone on the differentiation of membrane structure in cultured astrocytes. Glia 4, 335-344. doi: 10.1002/glia.440040402

Ledeboer, A., Brevé, J. J., Poole, S., Tilders, F. J., and Van Dam, A. M. (2000). Interleukin-10, interleukin-4, and transforming growth factorbeta differentially regulate lipopolysaccharide-induced production of proinflammatory cytokines and nitric oxide in co-cultures of rat astroglial and microglial cells. Glia 30, 134-142. doi: 10.1002/(sici)1098-1136(200004)30:2\& lt;134::aid-glia3\&gt;3.0.co;2-3

Ling, E. A., and Wong, W. C. (1993). The origin and nature of ramified and amoeboid microglia: a historical review and current concepts. Glia 7, 9-18. doi: 10.1002/glia.440070105

Lobo-Silva, D., Carriche, G. M., Castro, A. G., Roque, S., and Saraiva, M. (2017) Interferon- $\beta$ regulates the production of IL-10 by toll-like receptor-activated microglia. Glia 65, 1439-1451. doi: 10.1002/glia.23172

Malik, M., Parikh, I., Vasquez, J. B., Smith, C., Tai, L., Bu, G., et al. (2015). Genetics ignite focus on microglial inflammation in Alzheimer's disease. Mol. Neurodegenerat. 10:52. doi: 10.1186/s13024-015-0048-1

Meeuwsen, S., Bsibsi, M., Persoon-Deen, C., Ravid, R., and van Noort, J. M. (2005). Cultured human adult microglia from different donors display stable cytokine, chemokine and growth factor gene profiles but respond differently to a proinflammatory stimulus. Neuroimmunomodulation 12, 235-245. doi: 10.1159/ 000085655

Meeuwsen, S., Persoon-Deen, C., Bsibsi, M., Ravid, R., and van Noort, J. M. (2003). Cytokine, chemokine and growth factor gene profiling of cultured human astrocytes after exposure to proinflammatory stimuli. Glia 43, 243-253. doi: 10.1002/glia.10259

Moinfar, Z., Dambach, H., and Faustmann, P. M. (2014). Influence of drugs on gap junctions in glioma cell lines and primary astrocytes in vitro. Front. Physiol. 5:186. doi: 10.3389/fphys.2014.00186

Möller, C., Lücke, J., Zhu, J., Faustmann, P. M., and Von Der Malsburg, C. (2007). Glial cells for information routing? Cogn. Syst. Res. 8, 28-35. 
Na, K. S., Jung, H. Y., and Kim, Y. K. (2014). The role of pro-inflammatory cytokines in the neuroinflammation and neurogenesis of schizophrenia. Progr. Neuro-Psychopharmacol. Biol. Psychiatry 48, 277-286. doi: 10.1016/j.pnpbp. 2012.10.022

Nam, J., Koppinen, T. K., and Voutilainen, M. H. (2021). MANF Is Neuroprotective in Early Stages of EAE, and elevated in spinal white matter by treatment with dexamethasone. Front. Cell. Neurosci. 15:640084. doi: 10.3389/ fncel.2021.640084

Obuchowicz, E., Bielecka-Wajdman, A., Zieliński, M., Machnik, G., Gołyszny, M., and Ludyga, T. (2020). Imipramine and venlafaxine differentially affect primary glial cultures of prenatally stressed rats. Front. Pharmacol. 10:1687. doi: 10.3389/fphar.2019.01687

Okada, M., Fukuyama, K., Shiroyama, T., and Ueda, Y. (2019). Carbamazepine attenuates astroglial l-glutamate release induced by pro-inflammatory cytokines via chronically activation of adenosine A2A receptor. Int. J. Mol. Sci. 20:3727. doi: 10.3390/ijms20153727

Park, M. J., Park, H. S., You, M. J., Yoo, J., Kim, S. H., and Kwon, M. S. (2019). Dexamethasone induces a specific form of ramified dysfunctional microglia. Mol. Neurobiol. 56, 1421-1436. doi: 10.1007/s12035-018-1156-z

Patel, D. C., Tewari, B. P., Chaunsali, L., and Sontheimer, H. (2019). Neuron-glia interactions in the pathophysiology of epilepsy. Nat. Rev. Neurosci. 20, 282-297. doi: 10.1038/s41583-019-0126-4

Pavone, A., and Cardile, V. (2003). An in vitro study of new antiepileptic drugs and astrocytes. Epilepsia 44, 34-39. doi: 10.1046/j.1528-1157.44.s10.5.x

Peng, L., Li, B., and Verkhratsky, A. (2016). Targeting astrocytes in bipolar disorder. Expert Rev. Neurotherapeutics 16, 649-657. doi: 10.1586/14737175. 2016.1171144

Perriot, S., Mathias, A., Perriard, G., Canales, M., Jonkmans, N., Merienne, N., et al. (2018). Human induced pluripotent stem cell-derived astrocytes are differentially activated by multiple sclerosis-associated cytokines. Stem Cell Rep. 11, 1199-1210. doi: 10.1016/j.stemcr.2018.09.015

Petrasch-Parwez, E., Schöbel, A., Benali, A., Moinfar, Z., Förster, E., Brüne, M., et al. (2020). Lateralization of increased density of Iba1-immunopositive microglial cells in the anterior midcingulate cortex of schizophrenia and bipolar disorder. Eur. Arch. Psychiatry Clin. Neurosci. 270, 819-828.

Rao, K. V., Brahmbhatt, M., and Norenberg, M. D. (2013). Microglia contribute to ammonia-induced astrocyte swelling in culture. Metabolic Brain Dis. 28, 139-143. doi: 10.1007/s11011-012-9339-1

Réus, G. Z., Fries, G. R., Stertz, L., Badawy, M., Passos, I. C., Barichello, T., et al. (2015). The role of inflammation and microglial activation in the pathophysiology of psychiatric disorders. Neuroscience 300, 141-154. doi: 10. 1016/j.neuroscience.2015.05.018

Reuss, B., and Unsicker, K. (1998). Regulation of gap junction communication by growth factors from non-neural cells to astroglia: a brief review. Glia 24, 32-38.

Ryan, K. M., Boyle, N. T., Harkin, A., and Connor, T. J. (2020). Dexamethasone attenuates inflammatory-mediated suppression of $\beta 2$-adrenoceptor expression in rat primary mixed glia. J. Neuroimmunol. 338:577082. doi: 10.1016/j. jneuroim.2019.577082

Sanz-Blasco, S., Piña-Crespo, J. C., Zhang, X., McKercher, S. R., and Lipton, S. A. (2016). Levetiracetam inhibits oligomeric $A \beta$-induced glutamate release from human astrocytes. Neuroreport 27, 705-709. doi: 10.1097/WNR. 0000000000000601

Stienen, M. N., Haghikia, A., Dambach, H., Thöne, J., Wiemann, M., Gold, R., et al. (2011). Anti-inflammatory effects of the anticonvulsant drug levetiracetam on electrophysiological properties of astroglia are mediated via TGF $\beta 1$ regulation. Br. J. Pharmacol. 162, 491-507. doi: 10.1111/j.1476-5381.2010.0 1038.x

Sun, L., Fang, L., Lian, B., Xia, J. J., Zhou, C. J., Wang, L., et al. (2017). Biochemical effects of venlafaxine on astrocytes as revealed by $1 \mathrm{H}$ NMR-based metabolic profiling. Mol. Biosyst. 13, 338-349. doi: 10.1039/c6mb00651e

Takeda, K., Watanabe, T., Oyabu, K., Tsukamoto, S., Oba, Y., Nakano, T., et al. (2021). Valproic acid-exposed astrocytes impair inhibitory synapse formation and function. Sci. Rep. 11:23. doi: 10.1038/s41598-020-79520-7

Tynan, R. J., Weidenhofer, J., Hinwood, M., Cairns, M. J., Day, T. A., and Walker, F. R. (2012). A comparative examination of the anti-inflammatory effects of
SSRI and SNRI antidepressants on LPS stimulated microglia. Brain Behav. Immun. 26, 469-479. doi: 10.1016/j.bbi.2011.12.011

van den Ameele, S., van Diermen, L., Staels, W., Coppens, V., Dumont, G., Sabbe, B., et al. (2016). The effect of mood-stabilizing drugs on cytokine levels in bipolar disorder: a systematic review. J. Affect. Disord. 203, 364-373. doi: 10. 1016/j.jad.2016.06.016

van der Poel, M., Ulas, T., Mizee, M. R., Hsiao, C. C., Miedema, S., Adelia, et al. (2019). Transcriptional profiling of human microglia reveals grey-white matter heterogeneity and multiple sclerosis-associated changes. Nat. Commun. 10:1139. doi: 10.1038/s41467-019-08976-7

Vezzani, A., French, J., Bartfai, T., and Baram, T. Z. (2011). The role of inflammation in epilepsy. Nat. Rev. Neurol. 7, 31-40.

Vezzani, A., and Granata, T. (2005). Brain inflammation in epilepsy: experimental and clinical evidence. Epilepsia 46, 1724-1743.

Vezzani, A., Ravizza, T., Balosso, S., and Aronica, E. (2008). Glia as a source of cytokines: implications for neuronal excitability and survival. Epilepsia 49(Suppl. 2), 24-32. doi: 10.1111/j.1528-1167.2008.01490.x

Voet, S., Prinz, M., and van Loo, G. (2019). Microglia in central nervous system inflammation and multiple sclerosis pathology. Trends Mol. Med. 25, 112-123. doi: 10.1016/j.molmed.2018.11.005

Vollmar, P., Haghikia, A., Dermietzel, R., and Faustmann, P. M. (2008). Venlafaxine exhibits an anti-inflammatory effect in an inflammatory coculture model. Int. J. Neuropsychopharmacol. 11, 111-117. doi: 10.1017/ S1461145707007729

Walter, L., and Neumann, H. (2009). Role of microglia in neuronal degeneration and regeneration. Semin. Immunopathol. 31, 513-525. doi: 10.1007/s00281009-0180-5

Wang, C. H., Hsiao, C. J., Lin, Y. N., Wu, J. W., Kuo, Y. C., Lee, C. K., et al. (2014). Carbamazepine attenuates inducible nitric oxide synthase expression through Akt inhibition in activated microglial cells. Pharmaceutical Biol. 52, 1451-1459. doi: 10.3109/13880209.2014.898074

Wheeler, M. A., and Quintana, F. J. (2019). Regulation of astrocyte functions in multiple sclerosis. Cold Spring Harb. Perspect. Med. 9:a029009. doi: 10.1101/ cshperspect.a029009

Zemtsova, I., Görg, B., Keitel, V., Bidmon, H. J., Schrör, K., and Häussinger, D. (2011). Microglia activation in hepatic encephalopathy in rats and humans. Hepatology (Baltimore, Md.) 54, 204-215. doi: 10.1002/hep.24326

Zepeda, R., Contreras, V., Pissani, C., Stack, K., Vargas, M., Owen, G. I., et al. (2016). Venlafaxine treatment after endothelin-1-induced cortical stroke modulates growth factor expression and reduces tissue damage in rats. Neuropharmacology 107, 131-145. doi: 10.1016/j.neuropharm.2016.03.011

Zhao, M., Wang, F. S. L., Hu, X. S., Chen, F., and Chan, H. M. (2017). Effect of acrylamide-induced neurotoxicity in a primary astrocytes/microglial co-culture model. Toxicol. In Vitro 39, 119-125. doi: 10.1016/j.tiv.2016.11.007

Zychowska, M., Rojewska, E., Makuch, W., Przewlocka, B., and Mika, J. (2015). The influence of microglia activation on the efficacy of amitriptyline, doxepin, milnacipran, venlafaxine and fluoxetine in a rat model of neuropathic pain. Eur. J. Pharmacol. 749, 115-123. doi: 10.1016/j.ejphar.2014.11.022

Conflict of Interest: The authors declare that the research was conducted in the absence of any commercial or financial relationships that could be construed as a potential conflict of interest.

Publisher's Note: All claims expressed in this article are solely those of the authors and do not necessarily represent those of their affiliated organizations, or those of the publisher, the editors and the reviewers. Any product that may be evaluated in this article, or claim that may be made by its manufacturer, is not guaranteed or endorsed by the publisher.

Copyright (C) 2021 Ismail, Corvace, Faustmann and Faustmann. This is an openaccess article distributed under the terms of the Creative Commons Attribution License (CC BY). The use, distribution or reproduction in other forums is permitted, provided the original author(s) and the copyright owner(s) are credited and that the original publication in this journal is cited, in accordance with accepted academic practice. No use, distribution or reproduction is permitted which does not comply with these terms. 